\title{
A Study on the Trade-Economic Effects and Utilization of AEO Mutual Recognition Agreements
}

\author{
Chul-Hun LEE*, Moo-Yul HUH**
}

Received: January 01, 2020 Revised: January 30, 2020 Accepted: February 05, 2020.

\begin{abstract}
Purpose: The AEO (Authorized Economic Operator) program, created in 2001 in the United States due to 9.11 terrorist's attack, fundamentally changed the trade environment. Korea, which introduced AEO program in 2009, has become one of the world's top countries in the program by ranking 6th in the number of AEO certified companies and the world's No. 1 in MRA (Mutual Recognition Agreement) conclusions. In this paper, we examined what trade-economic and non-economic effects the AEO program and its MRA have in Korea. Research design, data and methodology: In this study we developed a model to verify the impact between utilization of AEO and trade-economic effects of the AEO and its MRA. After analyzing the validity and reliability of the model through Structural Equation Model we conducted a survey to request AEO companies to respond their experience on the effects of AEO program and MRA. As a result, 196 responses were received from 176 AEO companies and utilized in the analysis. Results: With regard to economic effects, the AEO program and the MRA have not been directly linked to financial performance, such as increased sales, increased export and import volumes, reduced management costs, and increased operating profit margins. However, it was analyzed that the positive effects of supply chain management were evident, such as strengthening self-security, monitoring and evaluating risks regularly, strengthening cooperation with trading companies, enhancing cargo tracking capabilities, and reducing the time required for export and import. Conclusions: When it comes to the trade-economic effects of AEO program and its MRA, AEO companies did not satisfy with direct effects, such as increased sales and volume of imports and exports, reduced logistics costs. However, noneconomic effects, such as reduced time in customs clearance, freight tracking capability, enhanced security in supply chain are still appears to be big for them. In a rapidly changing trade environment the AEO and MRA are still useful. Therefore the government needs to encourage non-AEO companies to join the AEO program, expand MRA conclusion with AEO adopted countries especially developing ones and help AEO companies make good use of AEO and MRA.
\end{abstract}

Keywords: AEO, MRA, Mutual recognition, Economic effects, Customs clearance procedure

JEL Classifications: E61, F13, F14, M21

1. 서론

우리나라는 작년에 3 년 연속으로 무역 1 조 달러를 돌파했다. 그간 지속적으로 무역을 증진해온 정부는 이를 무역 강국의 입지를 다진 것으로 평가했다. 이처럼 무역을 장려하고 지원하는 것은 우리나라만이

*First Author, Master of Dept. of Global Policy, Kongju National University, Korea Email: flag6632@naver.com

${ }^{* *}$ Corresponding Author, Professor, Dept of Global Policy, Kongju National University, Korea Tel: +82-41-850-0811,

Email: hmyag@kongju.ac.kr

๑ Copyright: Korean Distribution Science Association (KODISA)

This is an Open Access article distributed under the terms of the Creative Commons Attribution NonCommercial License (https:///creativecommons.org/licenses/by-nc/4.0/) which permits unrestricted noncommercial use, distribution, and reproduction in any medium, provided the original work is properly cited.
아니다. 모든 국가가 무역을 통해 이익을 얻는다. 국제 무역이 본격화된 제2차 세계대전 이후 글로벌 금융위기 등 몇 번의 부침은 있었지만 전 세계 무역량은 꾸준히 증가해왔다. 이러한 무역량 증가는 1970 년대에 시작된 무역원활화 논의와 1990 년대부터 본격화된 자유무역협정(Free Trade Agreement 이하 FTA) 덕분이라 할 수 있다.

이러한 무역의 원활화와 자유화를 위한 다양한 논의는 2001 년 9 월 11 일에 미국에서 발생한 항공기 테러(이하 9.11 테러)로 급격한 방향전환을 하게 된다. 이 사건은 화물을 운송하는 도구(항공기, 선박, 차량 등)가 테러의 수단으로 직접 활용되었다는 점에서 국제무역과 관련된 통상환경 전체에 큰 영향을 미쳤다. 9.11 테러 이듬해 미국은 
수입회물 및 운송수단을 통한 테러를 방지하기 위한 민관 협력프로그램을 즉각 마련하였다. 이른바, 테러방지 민관협력 프로그램(Customs-Trade Partnership Against Terorism, 이하 'C-TPAT) 이다.

세계관세기구(World Customs Organization, 이하 WCO)는 이 조치를 전 세계 차원의 논의로 확대시켰다. 테러 등 불법부정무역을 차단하기 위해 무역 안전과 무역원활화를 조화시키는 것은 모든 나라의 과제였기 때문이다. 2005 년 WCO 는 무역 안전과 관련하여 모든 회원국이 이행해야 할 기준을 채택했다. 이것이 바로 SAFE Framework of Standards to Seare and Fadiltate Global Trade (이하 'SAFE Framework)이다. 동 SAFE Framework 의 핵심은 국제물류의 안전과 원활화를 위해서 세관과 기업이 준수해야 할 기준을 정한 것이다. 이를 인가된 무역업자 제도(Authorized Economic Operator. 이하 'AEO)라 한다. AEO 제도는 두 가지 측면에서 큰 의미가 있다. 첫째 무역 안전과 관련된 기업과 수출입통관 처리 기준을 국제적으로 제정했다는 것이다. 따라서 $\mathrm{AEO}$ 로 인증된 기업은 非AEO 기업에 비해 세관 차원에서 다양한 혜택을 받을 수 있다. 둘째 $\mathrm{AEO}$ 제도를 도입한 국가들 간의 상호인정협정(Mutual Recognition Arrangement /Agreement, 이하 'MRA)을 체결할 경우 한 국가의 $\mathrm{AEO}$ 가 다른 국가에서도 $\mathrm{AEO}$ 로 대우를 받을 수 있다.

SAFE Framework 이 제정된 이후 AEO 제도와 MRA 는 전 세계에 급속도로 퍼져 나가고 있다. 2018 년말 현재 AEO 제도는 전 세계 83 개국이 도입했으며, 19 개국이 도입을 준비 중이다. AEO 상호인정협정도 꾸준히 증가하여, 2007 년 처음 체결되어 2016 년 44 개에 불과하던 것이 2019 년말 현재 74 개 MRA 가 체결되었고, 65 개가 협상 중이다.

우리나라도 미국, $\mathrm{EU}$, 일본, 중국 등 주요 무역 상대국에 이어 2009 년 AEO 제도를 도입했다. AEO 제도 도입 이유는 무역 안전을 핑계로 동 제도가 상대국에서 무역장벽으로 작용할 수 있다는 우려 때문이었다. 세관당국은 "신뢰성이 높은 $\mathrm{AEO}$ "에게는 통관절차 상 다양한 혜택을 주지만, 非AEO 기업은 중점 통제대상으로 삼게 된다. 인력과 자금력이 충분한 대기업들은 이에 대한 대응이 가능하나, 중소 기업들에게는 세관 통제가 통관 애로로 직결된다. 이에 따라 관세청은 $\mathrm{AEO}$ 제도 확산에 노력하는 한편, 미국 등 주요국과의 MRA 체결을 위해 노력을 해왔다. 이 결과 2019년 6 월 현재 우리나라는 832 개 업체를 공인하여 $\mathrm{EU}$, 미국, 중국, 캐나다, 멕시코 등에 이어 세계에서 6 번째로 공인 기업이 많은 AEO 강국이 되었다. 또한 2010 년 미국과의 MRA로 대외 신인도를 확보한 우리나라는 이후 일본, 중국, 인도, 멕시코, 터키 등 20 개국과 MRA 체결에 성공하여 2019년 말 현재 세계 1위 MRA 체결국이 되었다.

이와 같이 AEO 인증 기업 수와 MRA 체결 수라는 양적인 측면에서 우리나라는 세계에서 손꼽히는 $\mathrm{AEO}$ 강국이 되었다. 하지만 질적인 측면에서 이것이 어떤 경제적 의미를 갖는지는 검증되지 못한 것이 사실이다. 이에 따라 본 연구는 AEO MRA 가 어떤 경제적인 의미를
갖는지 그리고 이를 어떻게 활용하는 것이 바람 직 한지를 살펴보고자 한다.

\section{AEO 제도 및 MRA 에 대한 이론적 고찰}

\subsection{AEO 제도}

$\mathrm{AEO}$ 제도는 물품의 제조, 유통, 보관, 수출입통관 등 물류의 흐름과 관련하여 각 단계 마다 발생 가능한 위험을 사전에 인식하고 이를 방지할 수 있는 능력을 갖춘 물류 공급망 상의 업체를 국제기준에 맞추어 세관(당국)에서 공인하고, 이들 업체에게는 세관이 통관절차 간소화 등의 혜택을 부여하되 지속적으로 인증기준 준수 여부를 관리하여 물류 공급망의 안전과 무역 원활화를 구현하는 것을 말한다. 이는 세관 또는 민간업체의 일방적인 노력이 아닌 세관과 민간업체의 협력을 통해 물류 안전과 무역 원활화를 도모하는 것이다.

$\mathrm{AEO}$ 제도의 특징은 첫째 안전성과 신속성이다. AEO 제도를 도입함으로써 세관 절차가 보다 안전하고 신속하게 진행될 수 있다. 9.11 사태 이전에는 신속성에 초점을 두었지만, 이후에는 안전과 수출입신고의 정확성을 지향하고 있다. 둘째는 기업 중심의 위험관리다. $\mathrm{AEO}$ 제도는 과거 물품화물 중심의 위험관리를 기업의 신뢰도와 안전도 중심으로 전환시켰다. 셋째는 세관 영역의 확장이다. AEO 는 MRA 등 국가 간의 협력을 통해 세관 통제 영역이 국내에 한정되던 것을 국외까지 확장 시켰다. 넷째는 전체적 물류 안전 중심의 통합 관리다. $\mathrm{AEO}$ 제도를 통해 과거 특정 장소에서 단편적으로 시행되던 안전관리가 수출입 관련 무역 공급망 전체의 통합 관리로 전환되었다.

AEO 공인 기준은 WCO 에서 제정한 SAFE Framework 에 따라 (1) 법규 준수도, (2) 내부통제시스템, (3) 재무건전성, (4) 안전관리의 4 가지 분야로 구성되어 있고 각 국가마다 처한 현실에 맞춰 세부 내용은 조금씩 다르다.

AEO 공인 절차도 국가마다 약간 다르지만, 업체의 신청을 받아 서류심사 및 현장 심사를 통해 업체의 $\mathrm{AEO}$ 공인 기준 준수 능력 및 이행 가능 여부를 확인 후 공인한다. 서류심사는 AEO 공인 신청 업체가 제출한 신청 서류에 대해 공인 기준 충족 여부 등을 점검하며, 현장 심사는 1 차 서류심사를 통과한 AEO 신청 업체의 본사 및 해당 사업장을 방문하여 심사한다.

$\mathrm{AEO}$ 혜택은 WCO 의 가이드라인에 근거하여 크게 네 가지 원칙에 따라 부여한다. 첫째 공인 업체에 대한 혜택은 非 AEO 와 비교해서 명확한 차이가 있어야 한다. 둘째 공인 업체의 등급에 따라 차등화 된 혜택을 부여한다. 셋째 의미 있는 혜택이 주어져야 한다. 마지막으로 새로운 혜택을 꾸준히 개발한다. 


\subsection{AEO 상호인정제도 개요}

상호인정(Mutual Recognition)이란 "하나의 관세당국 (Customs Administration)에 의해 적합하게 취해진 실행, 결정 및 공인을 다른 관세 당국이 인정하고 수용하는 광범위한 개념"을 의미하며, 이러한 상호인정 결정 문서에 대해 서명하는 것이 상호인정협약(MRA)이다.

$\mathrm{AEO}$ 제도를 도입한 국가들 간에 MRA 체결이 필수적인 이유는 세 가지다. 먼저, 수출입 관련 업체들이 자신이 거래하는 국가에서 통관상의 혜택을 받기 위해서는 양국 관세당국 간 $\mathrm{AEO}$ 제도를 서로 인정하고 수용하여야 한다. 다음으로 MRA 체결로 자국 AEO 제도에 대한 국제적인 신뢰성과 안전성을 확보할 수 있다. 마지막으로 MRA를 통해 수출기업이 AEO 제도의 혜택을 최대한 향유할 수 있어 대외경쟁력이 제고된다.

MRA 에 따른 혜택은 다음과 같다. 첫째, MRA 로 우리나라 AEO 공인 기업이 상대국 통관절차에서 특례를 적용 받을 수 있다. 예를 들어 한중 MRA 에 따라 AEO 화물은 중국 세관을 통과하는데 걸리는 시간이 일반 회물보다 $80 \%$ 가량 단축된다. 둘째, 화보호무역 환경에서 AEO 기업은 거래선의 유지와 확보 측면에서 유리한 위치를 선점할 수 있다. 셋째, 외국 관세 당국의 해외 거래업체 방문 심사에 의해 업체의 기술, 시설, 영업 정보 등 소중한 자원이 해외에 직접적으로 노출되는 것을 방지할 수 있다. 실제로 미국 관세청(CBP)은 2002 년부터 2012 년 8 월말까지 우리나라를 170 여회를 방문하여 수출기업의 안전관리에 관한 심사를 실시한 바 있다.

WCO 는 MRA 추진 시 단계적 접근(phased approach)을 권장하고 있으며, 4 단계로 구분할 수 있다. 1 단계로 양국 간 AEO 공인 기준을 비교하고, 2 단계로 상대국 공인 업체를 방문하여 합동으로 심사하고, 3 단계로 혜택 및 정보공유 등 운영 절차에 대해 협의를 하게 되며, 마지막으로 양국 관세청장 간 상호인정 협정문을 작성하여 서명, 발표하게 된다.

\section{3. 선행연구 검토}

AEO 제도에 대한 논의는 Song (2006)의 『무역원활화와 국경 안전 강화를 위한 세관과 업계의 협력 사례 분석과 그 시사점』이 최초였다. 대학원 학위논문으로는 Lee (2010)의 『AEO 제도 확립 및 대응방안에 관한 연구』가 최초다.

Ahn (2008)은 미국, EU 에 이어 일본의 AEO 제도 추진 내용에 대한 분석 연구를 통해 우리나라의 AEO 제도 도입 시 시사점과 정책방향을 제시하였다. 그는 제도의 성공을 위해 다른 정부 부처와의 중복 방지와 업체의 부담 완화가 중요하다고 언급하면서 주요국과의 MRA 를
체결함으로써 우리 수출기업들이 해당국에서 신속 통관, 검사 완화 등을 통한 경쟁력을 극대화할 수 있도록 지원할 것을 강조하였다.

MRA 와 관련된 연구는 Jeong et al. (2010)이 우리나라가 외국과의 상호인정에 관한 논의를 착수할 무렵부터 시작되었다. 따라서 AEO 제도 자체에 대한 논에 비해 연구의 내용과 수가 다소 적다. 먼저 AEO 제도를 무역원활화 측면에서 검토하고 한중일 3 국의 AEO 상호인정협정에 주목하였다.

Yoon (2014)은 우리나라 AEO 제도의 국가 간 MRA 확대 방안에 대해 연구하였다. 저자는 한-중 간 AEO MRA 체결을 계기로 양국 MRA 가 무역원활화에 미치는 효과를 분석하여 중국 내에서 $\mathrm{AEO}$ 기업의 수출물품의 수입통관 소요시간이 50 60\% 절감되고, 세관 검사율도 대폭 낮아졌음을 밝혀냈다.

최근에 Kim (2016)은 기존 MRA 선행연구를 먼저 살펴본 뒤 이들의 문제점과 한계를 넘어 계량적인 분석을 도입하려 노력하였다. 이런 분석을 기반으로 저자는 향후 MRA 제도의 발전방향으로 가시적 혜택 확대, 국내 인증제도와의 연계, MRA 운영 내실화, 국가간 상호인정 확대를 향후 과제로 제시하였다.

선행연구 결과를 종합해 보면 AEO 제도와 MRA 의 경제효과는 크게 두 가지다. 먼저 미시적으로 (1) 물류비용 절감, 매출액 증가, 브랜드 제고 등 기업 측면의 효과, (2) 효과적인 위험관리를 통한 행정비용 절감 효과, (3) 안전한 물류 공급망 구축으로 국가 사회에 미치는 효과 등을 들 수 있다. 거시적으로는 (1) 수출입 및 무역수지 개선효과, (2) 경제성장 및 후생 수준 증진 효과, (3) 고용증진 효과, (4) 외국인 투자 효과 등을 들 수 있다.

\section{AEO 제도 및 MRA 의 경제적 효과}

\section{1. 연구 모형과 가설의 설정}

Table 1: Hypotheses of Study

H1 AEO program will have plus effects on AEO companies' performance.

H2 AEO MRA will have plus effects on AEO companies' performance.

H3 Effective use of the AEO program and MRA will have plus effects on the performance of the AEO companies.

H4 AEO program and MRA will vary depending on the size of the AEO company

H5 AEO program and MRA will vary depending on the business sector of the AEO company

본 연구는 AEO 제도와 MRA 가 경제적으로 의미가 있고, 기업의 성과와 연관되며, 이를 적절히 활용할 경우 기업의 성과가 배가될 수 
있는지를 검증하고자 하였다. 다만 이 때 기업의 성과는 기업의 업종 및 규모 등에 따라 다소 유동적일 수 있음을 상정하였다. 이 과정에서 AEO 제도와 MRA 의 경제적 또는 비경제적 효과와 이에 대한 효과적 활용방안에 대해서 살펴보았다.

이들 연구를 위해 설정한 가설은 <Table 1 >과 같다.

\section{2. 자료수집 방법 및 설문 구성}

본 연구를 위한 설문조사는 2019 년 6 월 3 일부터 8 월 30 일까지 834 개 업체의 AEO 기업을 대상으로 하였다. 이 중에서 설문에 응답한 업체는 176 개로 회수율은 $211 \%$ 이며 일부 업체에서는 2 명 이상의 담당자가 응답하여 총 176 개 업체 196 명의 설문서가 회수되었다. 다만, 설문에 대한 실증분석을 위해서 동일한 업체의 직원이라 하더라도 담당업무가 $\mathrm{AEO}$ 제도와의 관련도나 인지도에 따라 $\mathrm{AEO}$ 제도 및 MRA에 대한 만족도 등에 차이가 있을 수 있으며 향후 발전방향 등에 대한 의견이 다를 수 있으므로 설문 분석의 기준을 기업이 아닌 담당자로 하였다. 따라서 무효인 3 개 설문을 제외한 193 개의 설문서를 연구에 활용하였다.

설문은 AEO 제도의 효과재무성과, 공급망 관리, 대외경쟁력, 인증기준 등 7 개 분야), $\mathrm{AEO} \mathrm{MRA}$ 의 효과(재무성과, 공급망 관리, 대외경쟁력 등 3 개 분야), AEO MRA 활용방안(인지도 제고, 새로운 혜택, AEO 및 MRA 확산 등 4 개 분야), 그리고 기업 일반에 관한 사항 등 4 부분이며, 총 89 개 문항으로 되어 있다. AEO 제도의 효과, MRA 효과, MRA 활용방안은 1 강한 부정부터 4 보통, 그리고 7 강한 긍정까지 정도 선택을 할 수 있고, 기업 일반은 객관식이다.

\section{3. 모형에 대한 신뢰성 및 타당성 분석결과}

연구 모형에 대한 신뢰성과 타당성을 분석하기 위해 활용 가능한 독립변수와 종속변수를 도출해 보았다. 이를 위해 먼저 각 가설에서 유효한 요인을 판단한 결과 총 9 개의 요인들이 활용 가능한 것으로 파악되었다. 이를 바탕으로 독립변수는 AEO 활용 측면의 3 개 요인(1) $\mathrm{AEO}$ 의 혜택, (2) AEO/MRA 확산, (3) 인지도 제고)으로 하고, 종속변수는 $\mathrm{AEO}$ 효과 측면에서 4 개 요인(1) 인증기준, (2) 무역 공급망 관리능력, (3) 재무성과, (4) 대외경쟁력), 그리고 AEO MRA 효과 측면에서 2개 요인(1) 무역 공급망 관리능력, (2) 재무성과)을 활용하였다.

우선 가설에 대한 통계의 신뢰성을 분석하기 위해 SPSS 프로그램의 신뢰도 (크론바하 알파, Cronbach's alpha)를 활용하였다. 측정 변수의 타당성(Validity)은 탐색적 요인분석(EFA: Exploratory Factor Analysis)으로 검증하였다. 그 결과 $\mathrm{AEO}$ 활용, $\mathrm{AEO}$ 효과, MRA 효과 부문의 하위 변인에 대한 고유 값(eigenvalue)을 살펴보면, 모든 요인의 고유 값이 2223 3.699
사이로 측정 변수의 타당성이 충분히 높았다. 또한 요인 별 Cronbach's Apha 계수가 최소 0.8 이상으로 나와 신뢰성 분석결과 또한 매우 높은 수준으로 분석되었다.

\subsection{AEO 활용, AEO 효과, AEO MRA 효과 간의 영향관계를 검증}

본 연구에서는 $\mathrm{AEO}$ 활용, $\mathrm{AEO}$ 효과, $\mathrm{AEO} \mathrm{MRA}$ 효과 간의 영향관계를 검증하기 위하여 구조방정식 모형의 적합도 분석을 실시하였다.

Table 2: Structural Equation Model Verification Results

\begin{tabular}{|c|c|c|c|c|c|c|}
\hline \multicolumn{3}{|c|}{ Components } & \multirow{2}{*}{\begin{tabular}{|c|} 
Estimate \\
-0.461 \\
\end{tabular}} & \multirow{2}{*}{$\begin{array}{c}\text { S.E. } \\
0.225\end{array}$} & \multirow{2}{*}{$\begin{array}{l}\text { C.R. } \\
-1.925\end{array}$} & \multirow{2}{*}{$\frac{\text { adoption }}{\mathrm{X}}$} \\
\hline $\begin{array}{c}\mathrm{H} 1 \\
-1\end{array}$ & $\begin{array}{c}\text { New } \\
\text { benefits }\end{array} \rightarrow$ & $\rightarrow \quad$ AEO criteria & & & & \\
\hline $\begin{array}{c}\mathrm{H} 1 \\
-2 \\
\end{array}$ & $\begin{array}{c}\mathrm{AEO} \\
\text { expansion }\end{array} \rightarrow$ & $\rightarrow \quad$ AEO criteria & 0.417 & 0.088 & 3.564 & $\mathrm{O}$ \\
\hline $\begin{array}{c}\mathrm{H} 1 \\
-3\end{array}$ & $\begin{array}{c}\text { raise } \\
\text { awareness }\end{array} \rightarrow$ & $\rightarrow \quad$ AEO criteria & 0.778 & 0.317 & 2.853 & $\mathrm{O}$ \\
\hline $\begin{array}{c}\mathrm{H} 2 \\
-1\end{array}$ & $\begin{array}{c}\text { New } \\
\text { benefits }\end{array} \rightarrow$ & $\rightarrow \quad \begin{array}{c}\text { Capability of } \\
\text { SCM Mgt }\end{array}$ & -1.763 & 0.366 & -4.408 & $X$ \\
\hline \begin{tabular}{l|}
$\mathrm{H} 2$ \\
-2
\end{tabular} & $\begin{array}{c}\mathrm{AEO} \\
\text { expansion }\end{array} \rightarrow$ & $\rightarrow \quad \begin{array}{c}\text { Capability of } \\
\text { SCM Mgt }\end{array}$ & 0.489 & 0.135 & 2.655 & $\mathrm{O}$ \\
\hline \begin{tabular}{|l|}
$\mathrm{H} 2$ \\
-3
\end{tabular} & $\begin{array}{c}\text { raise } \\
\text { awareness }\end{array} \rightarrow$ & $\rightarrow \quad \begin{array}{c}\text { Capability of } \\
\text { SCM Mgt }\end{array}$ & 1.815 & 0.508 & 4.044 & $\mathrm{O}$ \\
\hline $\begin{array}{c}\mathrm{H} 3 \\
-1 \\
\end{array}$ & $\begin{array}{c}\text { New } \\
\text { benefits }\end{array} \rightarrow$ & $\rightarrow \quad \begin{array}{c}\text { Financial } \\
\text { performance }\end{array}$ & -2.364 & 0.625 & -5.036 & $\mathrm{X}$ \\
\hline $\begin{aligned} \mathrm{H} 3 \\
-2 \\
\end{aligned}$ & $\underset{\text { expansion }}{\mathrm{AEO}} \rightarrow$ & $\rightarrow \quad \begin{array}{c}\text { Financial } \\
\text { performance }\end{array}$ & 0.284 & 0.235 & 1.290 & $\mathrm{O}$ \\
\hline $\begin{array}{c}\mathrm{H} 3 \\
-3\end{array}$ & $\begin{array}{c}\text { raise } \\
\text { awareness }\end{array} \rightarrow$ & $\rightarrow \quad \begin{array}{c}\text { Financial } \\
\text { performance }\end{array}$ & 2.308 & 0.872 & 4.360 & $\mathrm{O}$ \\
\hline \begin{tabular}{c|}
$\mathrm{H} 4$ \\
-1 \\
\end{tabular} & $\begin{array}{c}\text { New } \\
\text { benefits }\end{array} \rightarrow$ & $\rightarrow$ Competitiveness & -2.459 & 0.531 & -4.923 & $\mathrm{X}$ \\
\hline $\begin{array}{c}\mathrm{H} 4 \\
-2 \\
\end{array}$ & $\begin{array}{c}\mathrm{AEO} \\
\text { expansion }\end{array} \rightarrow$ & $\rightarrow$ Competitiveness & 0.450 & 0.196 & 1.957 & $\mathrm{O}$ \\
\hline $\begin{array}{c}\mathrm{H} 4 \\
-3\end{array}$ & $\begin{array}{c}\text { raise } \\
\text { awareness }\end{array} \rightarrow$ & $\rightarrow$ Competitiveness & 2.487 & 0.740 & 4.420 & $\mathrm{O}$ \\
\hline \begin{tabular}{c|}
$\mathrm{H} 5$ \\
-1 \\
\end{tabular} & $\begin{array}{c}\text { New } \\
\text { benefits }\end{array} \rightarrow$ & $\rightarrow \begin{array}{c}\text { MRA Capability } \\
\text { of SCM Mgt }\end{array}$ & -2.042 & 0.481 & -4.786 & $\mathrm{X}$ \\
\hline \begin{tabular}{r|}
$\mathrm{H} 5$ \\
-2 \\
\end{tabular} & $\underset{\text { expansion }}{\mathrm{AEO}} \rightarrow$ & $\rightarrow \begin{array}{c}\text { MRA Capability } \\
\text { of SCM Mgt }\end{array}$ & 0.448 & 0.179 & 2.261 & $\mathrm{O}$ \\
\hline \begin{tabular}{|l|}
$\mathrm{H} 5$ \\
-3 \\
\end{tabular} & $\begin{array}{c}\text { raise } \\
\text { awareness }\end{array} \rightarrow$ & $\rightarrow \begin{array}{c}\text { MRA Capability } \\
\text { of SCM Mgt }\end{array}$ & 2.052 & 0.670 & 4.274 & $\mathrm{O}$ \\
\hline \begin{tabular}{|c|}
$\mathrm{H} 6$ \\
-1 \\
\end{tabular} & $\begin{array}{c}\text { New } \\
\text { benefits }\end{array} \rightarrow$ & $\rightarrow \begin{array}{c}\text { MRA Financial } \\
\text { performance }\end{array}$ & -2.687 & 0.587 & -5.262 & $\mathrm{X}$ \\
\hline \begin{tabular}{|l|}
$\mathrm{H} 6$ \\
-2
\end{tabular} & $\underset{\text { expansion }}{\mathrm{AEO}} \rightarrow$ & $\rightarrow \begin{array}{c}\text { MRA Financial } \\
\text { performance }\end{array}$ & 0.288 & 0.219 & 1.211 & $\mathrm{O}$ \\
\hline \begin{tabular}{c|}
$\mathrm{H} 6$ \\
-3 \\
\end{tabular} & $\begin{array}{c}\text { raise } \\
\text { awareness }\end{array} \rightarrow$ & $\rightarrow \begin{array}{c}\text { MRA Financial } \\
\text { performance }\end{array}$ & 2.566 & 0.816 & 4.465 & $\mathrm{O}$ \\
\hline
\end{tabular}

$\mathrm{AEO}$ 활용 요인과 $\mathrm{AEO}$ 효과 간의 관계를 검증하기 위하여 "AEO 활용은 AEO 효과의 인증기준에 유의한 정(+)의 영향을 미칠 것이다", "AEO 활용은 공급망 관리능력에 유의한 정(+)의 영향을 미칠 것이다", "AEO 활용은 AEO 효과의 재무 성과에 유의한 정(+)의 영향을 미칠 
것이다", "AEO 활용은 AEO 효과의 대외 경쟁력에 유의한 정(+)의 영향을 미칠 것이다"를 가설 1 , 가설 2 , 가설 3 , 가설 4 로 설정하였다. 또한 AEO 활용과 AEO MRA 효과 간의 관계를 검증하기 위하여 "AEO 활용은 AEO $\mathrm{MRA}$ 효과의 MRA 공급망 관리능력에 유의한 정(+)의 영향을 미칠 것이다", "AEO 활용은 AEO MRA 효과의 MRA 재무 성과에 유의한 정(+)의 영향을 미칠 것이다"는 가설 5 , 가설 6 을 설정하여 실증분석을 수행하였다. 그 결과 <Table 2>와 같은 결론을 도출하였다.

\section{5. 기업규모 또는 업종에 따른 MRA 효과 차이분석}

기업의 규모에 따라 AEO MRA 효과가 어떻게 다른지를 검증하기 위하여 "AEO 및 MRA 는 기업의 규모에 따라 차이가 있을 것이다."는 가설 4 를 설정하였다. 그 결과 기업의 규모, 즉 대기업인지 또는 중소기업인지에 따라 MRA 재무성과, 공급망 관리 역량, 대외경쟁력, 인증기준에 대한 효과에 의미 있는 차이가 있는 것으로 나타났다. 세부적으로 보면, MRA 재무 성과의 경우 대기업과 중견기업의 차이가 가장 크고, MRA 공급망 관리 역량과 대외경쟁력의 경우 중소기업과 대기업의 차이가 크게 나타났다. 따라서 가설 4는 채택되었다.

기업의 업종에 따른 AEO MRA 효과 차이를 검증하기 위하여 "AEO 및 $\mathrm{MRA}$ 는 기업의 업종에 따라 차이가 있을 것이다."는 가설 5 를 설정하였다. 그러나 기업의 업종, 즉 수출입기업인지 또는 물류기업인지에 따라 MRA 재무성과, 공급망 관리 역량, 대외경쟁력, 인증기준에 대한 효과에 큰 차이가 없는 것으로 나타났다. 따라서 가설 5 는 기각되었다.

\section{6. 설문결과 분석}

본 연구를 위해 실시한 설문조사 결과는 AEO 제도의 경제적 효과와 $\mathrm{MRA}$ 의 경제적 효과를 중심으로 살펴보았다. 설문에 대한 응답은 1 강한 부정부터 7 강한 긍정까지의 7 개 척도로 했고, 4 가 보통이다. 따라서 응답 "4 보통"은 '질문에 직접적으로 관련되지 않는 것'으로 해석했다.

AEO 제도의 효과 중 가장 직접적인 경제효과는 매출액, 수출입 규모, 관리비용, 영업이익, 거래기업(국가), 재정상황 등이다. 질문에 대한 답은 절반 가까이 '보통'이어서 AEO 인증과 이들 효과는 직접적인 관련은 없는 것으로 나타났다. 반면에 자체 보안, 공급망 위험, 부서간 협력 및 의사소통, 화물추적능력, 대 고객 이미지, 대 정부 관계, 기존고객 유지, 신규고객 유치, 법규준수, 납세 성실도, 안전관리 등 간접적 경제 효과 부분에 대해서는 긍정적인 답변이 압도적이었다.

먼저 AEO 제도의 경제효과는 <Table 3>과 같다.
Table 3: Effects of the AEO System

\begin{tabular}{|c|c|c|c|c|c|c|c|}
\hline \multirow{2}{*}{ Components } & \multicolumn{7}{|c|}{ Answers } \\
\hline & 1 & 2 & 3 & 4 & 5 & 6 & 7 \\
\hline an increase in sales & 6.1 & 5.6 & 7.7 & 52.6 & 15.8 & 8.7 & 3.6 \\
\hline $\begin{array}{c}\text { an increase in volume of } \\
\mathrm{im} / \text { export }\end{array}$ & 4.6 & 5.6 & 112 & 52.0 & 15.8 & 6.6 & 4.1 \\
\hline $\begin{array}{l}\text { an reduce in cost of } \\
\text { Management and } \\
\text { im/export }\end{array}$ & 6.6 & 9.2 & 13.8 & 47.4 & 12.8 & 6.1 & 4.1 \\
\hline $\begin{array}{l}\text { increase in operating } \\
\text { profit ratio }\end{array}$ & 5.6 & 8.2 & 12.8 & 51.0 & 143 & 4.6 & 3.6 \\
\hline $\begin{array}{l}\text { increase in number of } \\
\text { trading companies or } \\
\text { countries }\end{array}$ & 3.6 & 8.7 & 6.1 & 52.6 & 199 & 5.6 & 3.6 \\
\hline $\begin{array}{l}\text { an improvement in the } \\
\text { financial situation }\end{array}$ & 1.5 & 4.6 & 8.2 & 48.0 & 20.4 & 122 & 5.1 \\
\hline $\begin{array}{l}\text { self-security } \\
\text { enhancements }\end{array}$ & 0.0 & 1.0 & 2.0 & 9.7 & 30.1 & 372 & 199 \\
\hline prevent SCM Risk & 1.5 & 0.5 & 3.1 & 20.4 & 31.1 & 30.1 & 133 \\
\hline $\begin{array}{l}\text { change in risk } \\
\text { management policy }\end{array}$ & 0.0 & 0.5 & 2.0 & 14.8 & 34.7 & 31.1 & 16.8 \\
\hline $\begin{array}{l}\text { improving inter- } \\
\text { departmental cooperation }\end{array}$ & 0.5 & 1.5 & 4.1 & 235 & 34.7 & 24.5 & 112 \\
\hline $\begin{array}{c}\text { enhancing cooperation } \\
\text { with trading companies } \\
\text { within SCM }\end{array}$ & 0.5 & 1.5 & 3.6 & 33.7 & 265 & 25.0 & 9.2 \\
\hline $\begin{array}{l}\text { enhancing capability of } \\
\text { tracing freight }\end{array}$ & 1.0 & 1.5 & 3.1 & 29.1 & 28.6 & 26.0 & 10.7 \\
\hline $\begin{array}{l}\text { reducing time for } \\
\text { im/export }\end{array}$ & 1.0 & 4.6 & 7.7 & 372 & 21.9 & 19.4 & 8.2 \\
\hline $\begin{array}{l}\text { enhancing the image of } \\
\text { trading companies and } \\
\text { customers }\end{array}$ & 1.0 & 3.6 & 2.6 & 27.0 & 30.6 & 26.0 & 9.2 \\
\hline $\begin{array}{l}\text { improvement in } \\
\text { government relations }\end{array}$ & 0.0 & 4.1 & 3.1 & 28.6 & 30.6 & 25.0 & 8.7 \\
\hline $\begin{array}{l}\text { continuing business with } \\
\text { existing customers }\end{array}$ & 1.0 & 2.0 & 5.1 & 28.6 & 31.1 & 23.0 & 9.2 \\
\hline $\begin{array}{l}\text { help attract new } \\
\text { customers }\end{array}$ & 3.1 & 5.6 & 4.6 & 31.6 & 32.7 & 15.8 & 6.6 \\
\hline $\begin{array}{l}\text { enhancing Customs } \\
\text { related compliance }\end{array}$ & 0.0 & 0.5 & 0.5 & 143 & 29.6 & 32.7 & 22.4 \\
\hline $\begin{array}{l}\text { compliance with trade } \\
\text { related laws }\end{array}$ & 0.0 & 0.5 & 1.0 & 9.2 & 265 & 352 & 27.6 \\
\hline $\begin{array}{l}\text { risk evaluation and } \\
\text { monitoring }\end{array}$ & 0.0 & 1.0 & 1.5 & 10.7 & 28.6 & 32.1 & 26.0 \\
\hline $\begin{array}{l}\text { better inter-departmental } \\
\text { communication }\end{array}$ & 0.0 & 1.0 & 2.6 & 265 & 32.7 & 22.4 & 14.8 \\
\hline $\begin{array}{c}\text { improving integrity in } \\
\text { national or local tax } \\
\text { payment }\end{array}$ & 1.0 & 1.0 & 2.0 & 29.6 & 22.4 & 24.5 & 19.4 \\
\hline $\begin{array}{l}\text { improving overal security } \\
\text { management }\end{array}$ & 0.5 & 1.0 & 2.0 & 173 & 29.6 & 29.6 & 19.9 \\
\hline
\end{tabular}


AEO MRA 효과도 가장 직접적인 경제효과는 매출액, 수출입 규모, 관리비용, 거래기업(국가) 등이다. 이들 질문에 대한 답은 절반 이상이 '보통'이어서 AEO MRA 체결과 이들 효과는 직접적인 관련은 없는 것으로 나타났다. 반면에 글로벌 법규 준수의 중요성 인식, 공급 망상 업체와 협력강화, 부서간 협력 및 의사소통, 화물추적능력, 대 고객 이미지, 대 정부 관계, 기존고객 유지, 신규고객 유치 등 간접적 경제 효과 부분에 대해서는 긍정적인 답변이 압도적이었다.

다음으로 AEO MRA 효과는 <Table 4>와 같다.

Table 4: Effects of AEO MRA

\begin{tabular}{|l|c|c|c|c|c|c|c|}
\hline \multicolumn{1}{|c|}{ Components } & \multicolumn{7}{|c|}{ Answers } \\
\cline { 2 - 8 } & $\mathbf{1}$ & $\mathbf{2}$ & $\mathbf{3}$ & $\mathbf{4}$ & $\mathbf{5}$ & $\mathbf{6}$ & $\mathbf{7}$ \\
\hline $\begin{array}{l}\text { an increase } \\
\text { in sales }\end{array}$ & 3.6 & 6.1 & 5.6 & 64.3 & 8.7 & 9.7 & 2.0 \\
\hline $\begin{array}{l}\text { an increase in volume of } \\
\text { im/export }\end{array}$ & 3.1 & 6.1 & 6.1 & 61.7 & 12.8 & 8.2 & 2.0 \\
\hline $\begin{array}{l}\text { an reduce in cost of } \\
\text { Management and } \\
\text { im/export }\end{array}$ & 4.1 & 6.1 & 11.2 & 56.1 & 10.7 & 8.2 & 3.6 \\
\hline $\begin{array}{l}\text { awareness of global } \\
\text { compliance }\end{array}$ & 0.5 & 1.0 & 4.6 & 29.1 & 31.6 & 19.9 & 13.3 \\
\hline $\begin{array}{l}\text { requesting or } \\
\text { recommending AEO } \\
\text { accreditation }\end{array}$ & 1.5 & 3.1 & 6.6 & 39.8 & 24.0 & 17.9 & 7.1 \\
\hline $\begin{array}{l}\text { improving inter- } \\
\text { departmental cooperation }\end{array}$ & 0.5 & 2.6 & 6.1 & 39.8 & 23.5 & 20.9 & 6.6 \\
\hline $\begin{array}{l}\text { enhancing cooperation } \\
\text { with trading companies } \\
\text { within SCM }\end{array}$ & 1.0 & 2.0 & 6.6 & 41.3 & 22.4 & 18.4 & 8.2 \\
\hline $\begin{array}{l}\text { enhancing capability of } \\
\text { tracing im/export cargo }\end{array}$ & 1.5 & 2.0 & 3.6 & 37.2 & 26.5 & 17.3 & 11.7 \\
\hline $\begin{array}{l}\text { reducing time for } \\
\text { im/export }\end{array}$ & 2.0 & 4.1 & 8.7 & 41.3 & 20.9 & 14.3 & 8.7 \\
\hline $\begin{array}{l}\text { increase in number of } \\
\text { trading companies or } \\
\text { countries }\end{array}$ & 3.1 & 5.6 & 6.6 & 53.6 & 20.4 & 6.6 & 4.1 \\
\hline $\begin{array}{l}\text { enhancing the image of } \\
\text { trading companies and } \\
\text { customers }\end{array}$ & 1.0 & 3.1 & 4.6 & 34.7 & 30.1 & 17.3 & 9.2 \\
\hline $\begin{array}{l}\text { improvement in } \\
\text { government relations }\end{array}$ & 1.0 & 1.2 & 5.6 & 37.2 & 29.6 & 14.8 & 10.2 \\
\hline $\begin{array}{l}\text { continuing business with } \\
\text { existing customers }\end{array}$ & 2.0 & 1.0 & 5.1 & 40.3 & 24.5 & 17.9 & 9.2 \\
\hline $\begin{array}{l}\text { help attract new } \\
\text { customers }\end{array}$ & 6.1 & 38.8 & 25.0 & 17.9 & 6.1 \\
\hline
\end{tabular}

위에서 살펴본 것처럼 AEO 인증이나 MRA 체결이 매출규모, 수 출입 규모, 비용절감, 거래기업(국가) 수 등에 직접적으로 관련이 없다는 응답이 다수였다. 다만, 법규 준수도, 위험관리, 수출입 안전, 부서 간
또는 공급망 상 기업과의 의사소통 등 비경제적 혜택의 경우에는 많은 기업들이 AEO 제도와 MRA의 긍정적 효과를 실감하는 경향을 보였다. 이는 제도 운영의 효과 측면에서 매우 긍정적이고, 고무적이라 판단된다

\section{AEO MRA 의 활용방안}

앞서 살펴본 것처럼, MRA 는 다양한 효과가 있다. 자유무역협정(FA)은 국가 간 무역에서 관세를 철폐한다는 것을 요지로 하며「무역 비용 절감」이 핵심이다. 이에 반해 MRA 는 무역에서 세관검사(통제)를 생략한다는 것이 요지이며「소요시간 절감」이 핵심이다. 돈이 먼저냐 시간이 먼저냐 하는 것은 논쟁의 여지가 있을 수 있지만, 둘 다 중요하다는 것은 이론의 여지가 있다.

특히 우리나라의 주력 수출품인 반도체, LED, 휴대전화 등 고부가가치 하이테크 품목일수록 시간의 중요성이 크다. 이들 물품의 경우 운임이 최대 30 배나 비싼 데도 불구하고 저렴한 선박 대신 항공기로 운송하는 이유가 그것이다.

하지만 MRA 는 다양한 문제점을 가지는 것도 또한 사실이다. 이에 본 연구에서는 MRA에 집중하여 이와 관련된 문제점은 무엇인지 알아보고, 이를 무역원활화의 수단으로 적절히 활용할 수 있는 방법이 무엇인지 살펴보고자 한다.

\section{1. $\mathrm{MRA}$ 의 문제점}

먼저 AEO 제도 및 MRA 혜택은 그 크기를 직접적으로 계량하기가 쉽지 않다. AEO 제도 및 MRA 혜택은 무역 안전을 목적으로 세관에서 非AEO 기업의 화물에 대해 행사하는 통관 검사 등 불이익만큼을 AEO 기업이 향유하는 "반사적 이익"이자 "상대적 이익"이라고 해야 한다. 즉 AEO 기업의 세관검사 비율이 非 AEO 기업에 비해 현격히 낮은 건 사실이지만, $\mathrm{AEO}$ 기업들은 이런 세관의 차등 대우를 혜택 이라 기 보다는 '당연한 권리'로 여기는 경향이 있다.

다음으로 MRA 효과를 극대화하기 위해서 사전준비를 위한 시간과 충분한 지원이 필수적인데 그렇지 못하다. 즉 상대국과의 무역량, 현지 비관세장벽과 통관애로 파악, 상호인정 체결에 따른 효과 산정, 상대국 $\mathrm{AEO}$ 제도의 수준과 상호인정 체결 의지 파악 등 사전 절차에 많은 노력과 시간이 필요하다.

또한 MRA 의 혜택을 받기 위해 수출기업이 상대국에 제공하는 정보와 적용 절차 등이 국가마다 달라 혼란스럽다. 수출기업은 국가별로 다른 요구에 맞춰 정보를 제공하고 기재 요령을 준수해야 해서 복잡하고 번거롭다. 
$\mathrm{AEO}$ 및 $\mathrm{MRA}$ 혜택이 대기업에 집중되는 경향이 있다. 정부는 중소기업의 $\mathrm{AEO}$ 인증을 지원하며 제도 참여를 독려해 왔지만 실제로 중소기업의 참여는 많지 않고 중소기업의 무역규모가 대기업에 비해 현저히 적기 때문이다.

마지막으로 MRA 혜택은 세관의 통관 절차에 한정된다. 무역과 관련된 화물은 무역공급망을 거치면서 세관 외에 다양한 수출입 요건 기관과 관련되므로 MRA의 파급력은 제한적일 수밖에 없다.

\subsection{MRA 의 효과적 활용 방안}

MRA 를 효과적으로 활용하는 방안을 협상 단계와 실제 이행 단계, 그리고 활용 단계로 나누어 살펴보고자 한다.

먼저, 협상단계에서는 상대국의 통관애로 등을 파악하여 의미 있는 혜택을 최대한 발굴하고, 상황이 허락하는 경우 상대국 $\mathrm{AEO}$ 기업들에 대한 위험도를 평가해보는 것이 바람직하다.

이행단계에서는 MRA 체결 후 문제점을 사전에 해소하기 위해 시범운영을 실시하는 것이 매우 중요하다. 또한 MRA 협정문 외에 구체적인 혜택의 종류, $\mathrm{AEO}$ 인증업체정보 교환 방법, 시범운영 내용 및 절차, 사후 이행점검 절차 등 실무자를 위해 협정의 이행과 관련된 세부사항을 문서화 하여야 한다. 아울러 협정의 이행을 보장하기 위해 이행상황을 주기적으로 점검하여야 한다.

활용단계에서는 먼저 국내기업 중 AEO 인증 기업의 수를 늘리는 것이 매우 시급하고 중요하다. 그리고 상대국에서 관세 당국의 협조를 받아 양국의 수출입 관련 기업들을 모아 놓고 $\mathrm{MRA}$ 활용방안에 대해 설명하는 것이 필요하다. 마지막으로 양자간 $\mathrm{MRA}$ 는 협상과 체결 그리고 이행에 시간과 노력이 많이 소요되고, 절차가 복잡해지는 측면이 있으므로 다자간 MRA 논의를 본격적으로 연구할 필요가 있다.

\section{5. 결론 및 향후 과제}

경제적 효과와 관련하여 $\mathrm{AEO}$ 제도와 $\mathrm{MRA}$ 가 매출증가, 수출입 규모의 증가, 관리비용 절감, 영업 이익률 증가 등과 같은 재무적 성과와 직접적으로 연결되지는 않는 것으로 나타났다. 하지만, 자체 보안을 강화하고, 위험에 대한 모니터링과 평가를 주기적으로 실시하고, 거래업체와의 협력을 강화하고, 화물추적능력이 제고되고, 수출입 소요시간이 절감되는 등 공급망 관리 측면의 긍정적인 효과는 분명한 것으로 분석되었다.

기업의 규모별 효과 측면에서는 대기업군에서만 매출증가, 수출입 규모 증가, 관리비용 절감, 영업 이익률 증가 등의 효과가 집중되어
있었다. 특히 관리비용 측면에서 중소기업들은 $\mathrm{AEO}$ 인증을 받을 경우 오히려 비용이 증가하는 부작용이 있었다. 그나마 다행인 것은 공급망 관리 측면에서는 중소기업과 대기업을 가리지 않고 모든 기업들이 효과를 보는 것으로 나타났다.

기업의 업종별 효과 측면에서는 업종에 따라 큰 차이가 없었다. 다만 수출입 기업군에서는 매출증가, 수 출입 규모 증가, 관리비용 절감, 영업 이익률 증가 등의 효과가 뚜렷했다. 공급망 관리 측면에서는 업종과 관계없이 모든 기업들이 효과를 보고 있었다.

연구의 한계와 관련, $\mathrm{AEO}$ 제도 및 $\mathrm{MRA}$ 의 효과를 분석하다 보니 계량화할 수 있는 것, 그 중에서도 경제적으로 의미 있는 것에 초점을 둘 수밖에 없었다. 그러나 "세관과의 관계 개선", "화물추적능력 제고"와 같이 도움이 되지만 효과를 수치로 계량화하기 어려운 것도 분명히 있다. 이런 부분에 대한 연구가 이번 연구에서 충분히 다뤄지지 못했던 것을 안타깝게 생각한다. 또한 MRA 의 경우는 상대국이 있기 때문에 이에 따른 경제적인 효과를 제대로 측정하기 위해서는 MRA와 관계된 양국 정부와 $\mathrm{AEO}$ 기업들이 모두 참여한 가운데 공동 프로젝트로 추진하는 것이 바람직하다. 향후 이 부분에 대한 연구가 제대로 이루어지길 희망한다.

\section{References}

Ahn, J. J. (2008). A Study on Mutual Recognition Strategy of AEO Program: several examples and its implications for Korea Customs Service, The Journal of Korea Research Society for Customs, 9(3), 73-101.

Jeong, H. G., Na, S. K., \& Noh, Y. Y. (2010). Collaborative management cooperation among Korea, China and Japan for the revitalization of trade resources: Focusing on ways to promote mutual recognition of the AEO system, Northeast Asia Research 10, Seoul, Korea: KIEP.

Kim, C. B. (2016). AEO MRA Effect Measurement and Implementation Enhancement Plan, the Korea Customs Service Research Report. Seoul, Korea: The IndustrialAcademic Cooperation Group of Chung-Ahng University.

Lee, I. J. (2010) A Study on Expansion of AEO Program and Counter Measurements against the Change in Trade Environment, Seoul, Korea: Master's Thesis, Korea University.

Song, S. U. (2006). A Case Study on the Cooperative Relationship between Customs and Businesses for Security and Facilitation, The Journal of International Trade \& Commerce, 31(5), 239259

Yoon, Y. G. (2014). A Study on the Expansion of Mutual Recognition Agreements in Korea's AEO System, Seoul, Korea: Master's Thesis, Korea University. 